\title{
Investigating the Effects of Geometry in Solar Thermal Absorber Plates with Micro- Channels
}

\author{
Oyinlola, M.A*, Shire, G.S.F. and Moss R.W.
}

School of Engineering, University of Warwick, Gibbet Hill Road, Coventry, UK, CV4 7AL

\section{*M.A.Oyinlola@warwick.ac.uk,}

\begin{abstract}
Experimental studies were carried out to investigate the effects of micro-channel geometry on the thermal and hydraulic performance of absorber plates for compact (thin and light-weight) solar thermal collectors. Three plates with channel depths $0.25 \mathrm{~mm}, 0.5 \mathrm{~mm}$ and $1 \mathrm{~mm}$ were studied. Each plate had sixty channels which were $270 \mathrm{~mm}$ long and $2 \mathrm{~mm}$ wide. Experiments were run at typical operating conditions for flat plate solar collectors. The results showed a Reynolds number dependent Nusselt number; this was due to axial thermal conduction. The Nusselt number was observed to increase as the aspect ratio approached unity. Measured friction factors were similar in trend to the predictions for rectangular channels, although the overall rise in fluid temperature resulted in slightly lower friction factors. The plate with $0.25 \mathrm{~mm}$ deep channels was found to have best thermo-hydraulic performance; thermo-hydraulic performance reduced slightly with increase in hydraulic diameter. The results showed that thermal improvement can be achieved by increasing the fluid velocity, however, pumping the thermal fluid above a pump power per plate area of 0.3 $\mathrm{W} / \mathrm{m}^{2}$ resulted in marginal improvement. The results are beneficial for the design of microchannel absorber plates.
\end{abstract}

Keywords: Micro-channel; Solar Absorber plate; Laminar; Geometry; Heat transfer

\section{Nomenclature}

$\begin{array}{ll}A_{p} & \text { Plate area }\left(\mathrm{m}^{2}\right) \\ a & \text { Channel depth }(\mathrm{m}) \\ b & \text { Channel width (m) } \\ c_{p} & \text { Specific heat capacity }(\mathrm{J} / \mathrm{kg} \mathrm{K}) \\ D_{h} & \text { Hydraulic diameter }(\mathrm{m}) \\ \mathrm{Ex} & \text { Experiment } \\ \mathrm{f} & \text { Friction factor }(-) \\ h & \text { Heat transfer coefficient }\left(\mathrm{W} / \mathrm{m}^{2} \mathrm{~K}\right) \\ k_{f} & \text { Thermal conductivity of fluid }(\mathrm{W} / \mathrm{m} \mathrm{K}) \\ L & \text { Length of channel }(\mathrm{m}) \\ L_{t} & \text { Thermal entry length (m) } \\ \dot{m} & \text { Mass flow rate }(\mathrm{kg} / \mathrm{s}) \\ N_{c} & \text { Number of channels in plate }(-) \\ N u & \text { Nusselt number }(-) \\ P r & \text { Prandtl number }(-) \\ P & \text { Pumping power }\left(\mathrm{W} / \mathrm{m}^{2}\right) \\ P o & \text { Poiseuille number }(-)\end{array}$

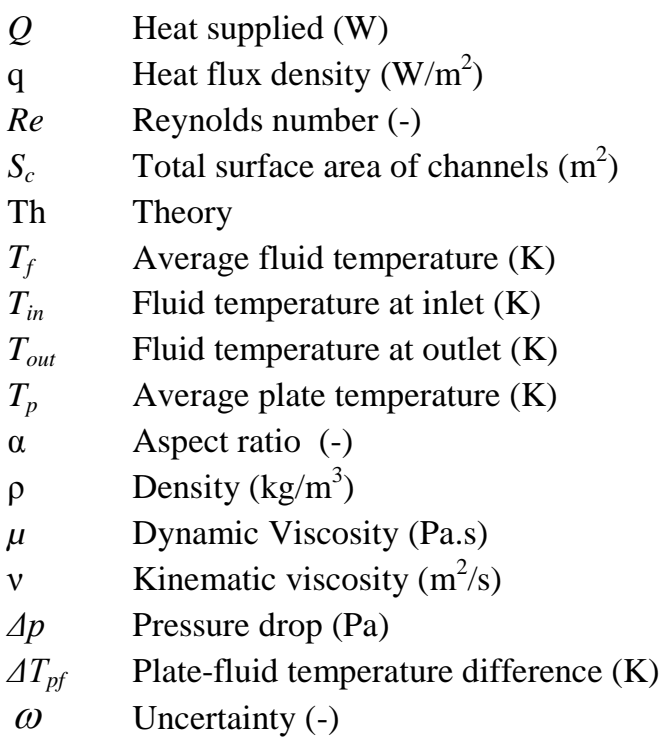

\section{Introduction}

Compact flat plate collectors (CFPC), utilizing metal sheets with micro-channels as absorber plates, offer considerable advantages for building-integrated solar thermal energy. In addition to achieving the compact size, this design has the advantage of enhanced convective heat 
transfer (based on the premise that the heat transfer coefficient is inversely proportional to the channel's hydraulic diameter) compared with the conventional arrangement of tubes bonded to a metal sheet. Celata's [1] definition of a micro-channel as a channel whose hydraulic diameter lies between $1 \mu \mathrm{m}$ and $1 \mathrm{~mm}$ is adopted in this study.

Several scholars have published various approaches to building integration of solar systems Tripanagnostopoulos et al. [2] investigated FPCs with coloured (black, blue and red brown) absorbers, they wanted to make FPCs aesthetically acceptable with respect to architectural designs; they recorded high thermal losses in the unglazed collectors but used flat booster reflectors to increase the radiation falling on the collectors. Matuska and Sourek [3] compared the thermal behaviour of façade collectors with standard roof mounted collectors and concluded that façade collectors should have approximately $30 \%$ greater area than similar standard FPC in order to have comparable capacity output. They noted that façade collectors also affect the indoor comfort of buildings by limiting the increase in temperature to no more than $1 \mathrm{~K}$ in all their investigated configurations. A low cost solar water heating system using cement concrete was studied by Chaurasia [4]; the system produced water which varied from $36{ }^{\circ} \mathrm{C}$ to $58{ }^{\circ} \mathrm{C}$. A comprehensive review of various approaches to building integration of solar systems is presented by Hestnes [5].

Several studies dedicated to optimising absorber plates have been carried out; Kundu [6] did a detailed comparative study on absorber plates of different geometry and Farahat et al. [7] performed a detailed energy and exergy analysis by varying various geometrical parameters. There is however limited work in the literature on the application of micro-channels to solar systems. Some of the few researchers who have published work in this area include Khamis Mansour [8]; who looked at flat plate rectangular channelled absorber plate and observed an increase of $16.1 \%$ in the heat removal factor compared with a conventional flat plate collector. Sharma and Diaz [9] modelled an evacuated tube collector based on mini channels and noted a gain of up to $20.7 \%$ in thermal efficiency compared with a similarly sized evacuated tube collector. Deng et al. [10] studied a novel FPC with micro-channel heat pipe array and recorded annual average system efficiency of 58.29\%.

The theory and correlations for heat transfer and fluid flow in conventional sized rectangular channels are well established; constant Nusselt number in the range $0.457-8.235$, with the exact value depending on the wall boundary conditions, are expected for fully developed laminar flow [11, 12]. Similarly in terms of friction factor, constant Poiseuille numbers in the range 56.92 - 96.00 are expected for rectangular channels with aspect ratios ranging from 0 - 1 . Extensive studies over the past three decades have however produced very inconsistent results. Some studies have found the average Nusselt number to be Reynolds number dependent in the laminar regime [13-15], some recorded lower Nusselt numbers [16-18] while some recorded higher Nusselt numbers [19-22]. Reviews on experimental and numerical studies of heat transfer in micro-channels published by Morini [23], Hetsroni et al. [24], Rosa et al. [25] and Sobhan and Garimella [26] confirm the very large scatter in published results and attribute it to scaling effects. In fact, quite recently, Dixit and Ghosh [27] who presented the state of the art on heat transfer in micro and mini channels, noted that standard design and analysis 
methodology for miniaturised channels, whether using theoretical or experimental techniques, are not yet available.

These scaling effects can be influenced by the design and application, therefore the performance of the micro-channel heat sink has to be tested for the particular application. The extensive study on micro-channels has been largely in the context of cooling electronic components. The peculiarities of the application of micro-channel heat transfer in solar collectors include low Reynolds numbers as well as the low heat flux densities. Most of the previous work done have been conducted for higher flow rates (typically $R e>100$ ) and higher heat fluxes (typically $q>10,000 \mathrm{~W} / \mathrm{m}^{2}$ ). Low Reynolds flow microfluidic heat exchange has been studied by a few including Dixit and Ghosh [16] and Wu and Cheng [28]. Wu and Cheng [28] observed that the Nusselt number increases almost linearly with Reynolds number at $R e<100$, but increases slowly at $R e>100$. The present study focuses on flows with $R e<100$ and $q<1000 \mathrm{~W} / \mathrm{m}^{2}$.

The importance of the micro-channel geometry has been highlighted by many; Naphon and Khonseur [29] concluded that the micro-channel geometry configuration has significant effect on the enhancement of heat transfer and pressure drop. Dogruoz et al. [30] stated that the wall heat transfer coefficient shows more dependence upon geometry than upon flow rate. Moss and Shire [31] presented a theoretical method for identifying the optimum channel size based on pumping power limit. This paper therefore investigates the effects of the channel geometry on the overall performance. Three plates with channels having the same width but different depths were used in this study. The results of this study are beneficial for the design of micro-channel absorber plates.

\section{Theory}

The collector efficiency factor $F$ ' is a parameter often used to characterise flat plate collectors. $F$ ' represents the ratio of the useful energy gain to the useful gain that would result if the collector absorbing surface had been at the local fluid temperature [32, 33]. Therefore, the convective heat transfer coefficient, $h$, which determines the temperature difference between the absorber plate and the fluid, is a good parameter for characterising the thermal performance of the plates; the higher the heat transfer coefficient, the lower the temperature difference between plate and fluid, the better the thermal performance of the plate. The heat transfer coefficient depends on several factors including fluid properties, fluid velocity, surface roughness and geometry [11,34]. The performance can be enhanced both at the design (geometry and surface roughness) and operation phases (fluid properties and fluid velocity). The main focus of this paper is on enhancing the performance by optimal geometry design.

A numerical investigation for Nusselt numbers for laminar flow in rectangular channels under H1(constant axial wall heat flux with constant peripheral wall temperature) boundary condition was presented by Shah and London [11]. Similarly, Dharaiya and Kandlikar [35] numerically investigated the $\mathrm{H} 2$ (constant axial wall heat flux with uniform peripheral wall heat flux) boundary condition in rectangular channels. These boundary conditions represent the theoretical limits for different 4-wall conductivity cases; the experiment should fall between them. Figure 1a shows plots of Nusselt numbers against aspect ratios for H1[11] and H2 [35] 
wall boundary conditions. This figure suggests that if these heat transfer correlations apply in this design of absorber plates, there is significant scope for improving the heat transfer by varying the aspect ratio. It can be observed from this figure that the trend of Nusselt number with aspect ratio differs depending on the wall boundary condition; some conditions yield an increase in Nusselt number with aspect ratio while others yield reduction in Nusselt number with aspect ratio.

Solar collectors are often characterised by low flow velocities to minimise the (electrical) pumping power required. There is however a trade-off between low pumping power and reduced performance due to temperature rise in the fluid. Fully developed laminar flow will be expected in these channels because of the low flow velocities and the micro scale of the hydraulic diameter. This implies that constant Nusselt number correlation for fully developed laminar flow can be expected. Rearranging equation 8, the heat transfer coefficient can be expressed as

$h=\frac{k N u}{D_{h}}$

Therefore, if the fluid properties can be assumed constant, a reciprocal relationship will be expected between the heat transfer coefficient and the hydraulic diameter. This suggests that improvements in heat transfer coefficient can be achieved by reducing the hydraulic diameter. A corresponding $\Delta T_{p f}<1^{\circ} \mathrm{C}$, can also be expected from the range of hydraulic diameters studied. Furthermore, by varying the hydraulic diameter by about $1 \mathrm{~mm}$ as well as changing the aspect ratio, up to $300 \%$ increase in heat transfer coefficient can be achieved. Figure 1b shows the corresponding heat transfer coefficient expected at various hydraulic diameters for two extreme Nusselt number correlations. This graph suggests that varying the aspect ratio can result in up to $65 \%$ increase in heat transfer coefficient.

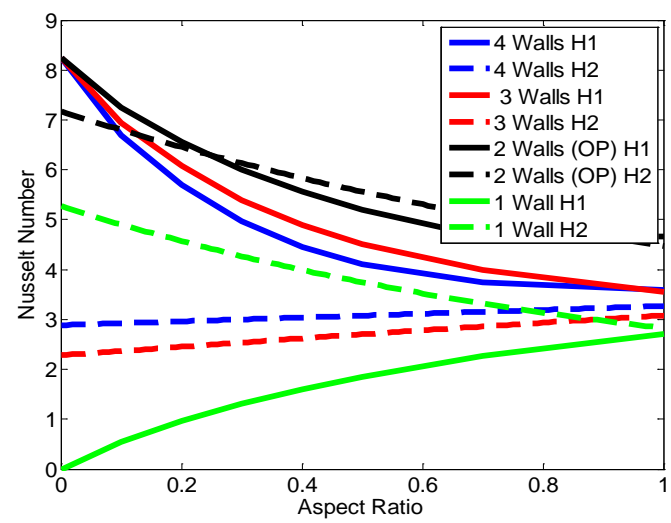

(a)

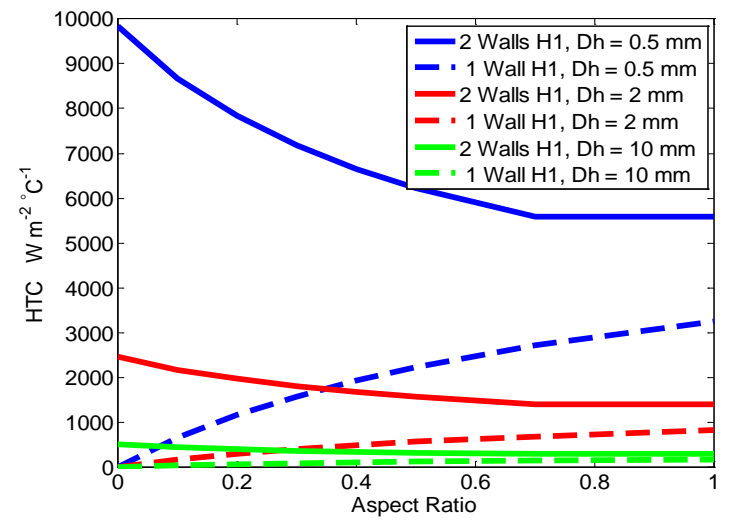

(b)

Figure 1: (a) H1 and H2 Nusselt numbers versus Aspect ratio [11, 35] (b) Predicted heat transfer coefficient

Hydraulic performance is another characteristic that influences plate design. If the energy output is to be maximised, the least possible power must be expended on pumping the fluid. The friction factor is often used to characterise the hydraulic performance of fluid flow through ducts. In laminar flow, the friction factor is directly proportional to the Poiseuille number and 
inversely proportional to the Reynolds number. The Poiseuille number is expected to be constant for a particular aspect ratio and also reduces as aspect ratio tends to unity.

\section{Experimental Apparatus}

\subsection{Description of the experimental system}

A setup representative of the proposed system was designed for experimental investigation. Figure 2a shows a flow schematic of the experimental facility; a temperature controlled circulating bath supplied the heat transfer fluid (Tyfocor ${ }^{\circledR}$ LS, a propylene glycol-based heat transfer fluid for solar collectors) at constant flow rate and temperature to a micro-channel test rig. Instruments to measure the temperature at different points, the pressure drop across the test rig and the mass flow rate were embedded at appropriate locations in the loop. The actual experimental setup is shown in Figure $2 b$.

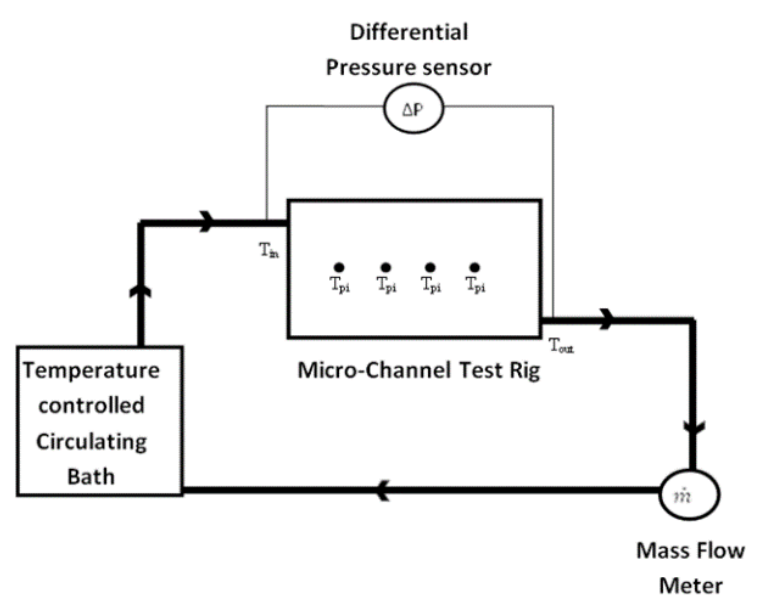

(a)

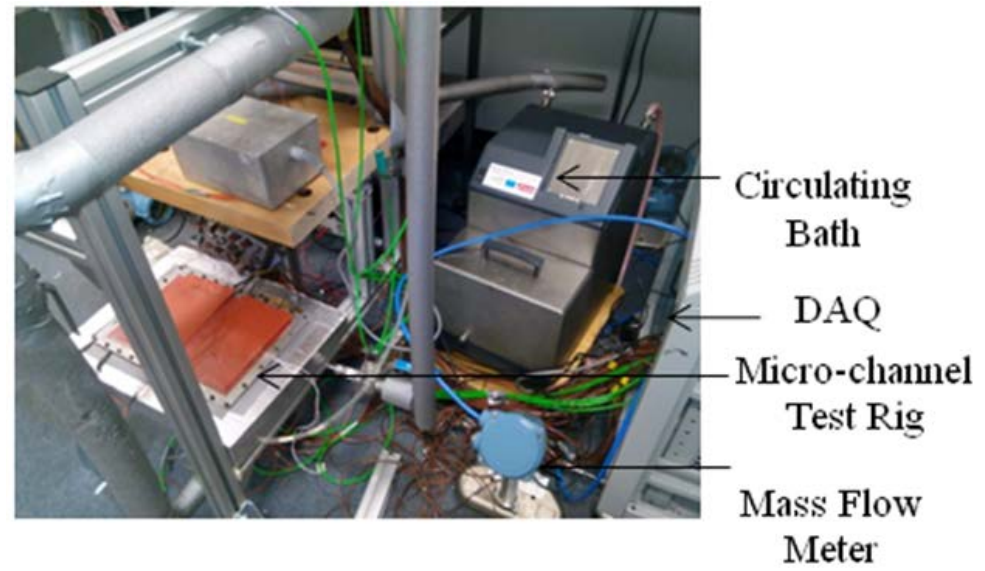

(b)

Figure 2: (a) Flow Schematic (b) Experimental apparatus

The main component of the experimental setup was the micro-channel test rig which simulated the flat plate collector. It was made up of two $340 \times 240 \times 10 \mathrm{~mm}$ aluminium slabs $-\mathrm{a}$ "top" and "bottom" piece, with a thinner $(3 \mathrm{~mm})$ channel plate sandwiched between them, as shown in Figure 3. This arrangement allowed a variety of relatively simple channel plates to be tested without each needing its own inlet and outlet connections.

Incident solar radiation was simulated with a self-adhesive heater mat, capable of supplying up to $1200 \mathrm{~W} / \mathrm{m}^{2}$, mounted on the top slab. All the data in this paper were obtained with a heater power of about $70 \mathrm{~W}$, equivalent to $950 \mathrm{~W} / \mathrm{m}^{2}$. The rig was insulated with a box constructed from Polyisocyanurate foam. The channels and manifolds were designed as a $\mathrm{Z}$ type heterogeneous ladder with two scale resistance; from the model presented by Tondeur et al. [36], the mal-distribution in the channels is expected to be less than $20 \%$. 


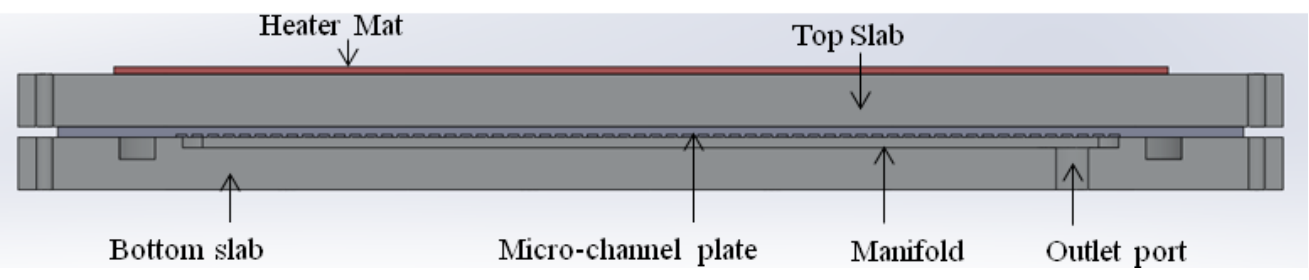

Figure 3: Cross section of test rig

Table 1 shows geometry details of the channels machined on the three plates, while the channels on the plate can be seen in Figure 4a. Temperatures of the plate at different points $\left(T_{p i}\right)$, fluid at inlet $\left(T_{i n}\right)$ and fluid at outlet $\left(T_{\text {out }}\right)$ were measured using Type $\mathrm{T}$ thermocouples. Several thermocouples were fixed on the absorber plate using fibre-glass thermal attachment pads, as shown in Figure 4b. Thermocouples were placed inside the inlet and outlet ports after elbow fittings (to promote fluid mixing) for accurate readings of bulk fluid temperature. All pipes and fittings were properly insulated to minimise heat loss to the ambient. The flow rate $(\dot{m})$ and pressure drop $(\Delta p)$ were measured using a Coriolis mass flow meter and a differential pressure sensor respectively. All the measured quantities were logged with a 16-bit National Instruments data acquisition system via Labview. Thermocouples were connected through a SCXI-1102 thermocouple interface board. Signals were sampled at $2 \mathrm{~Hz}$; signal quality was studied using an oscilloscope to ensure they were clean and free from interference. Post steady state data were used for analyses. The criterion for steady state was defined by $\frac{d T}{d t}<2.5 \times$ $10^{-5}{ }^{\circ} \mathrm{C} / \mathrm{s}$; this was reached after approximately $10-15$ minutes at a constant flow rate. The enthalpy change of the fluid was used to calculate the heat flux. The power consumed by the heater mat was measured using a voltmeter and ammeter; the heat flux as defined by flow measurement was within $10 \%$ of power consumed.

Table 1: Geometric parameters of the channels

\begin{tabular}{llllllll}
\hline Plate & $\boldsymbol{a}(\mathbf{m m})$ & $\boldsymbol{b}(\mathbf{m m})$ & $\boldsymbol{p}(\mathbf{m m})$ & $\boldsymbol{D}_{\boldsymbol{h}}(\mathbf{m m})$ & $\boldsymbol{L} \mathbf{( m m})$ & $\boldsymbol{\alpha}$ & $\boldsymbol{N}_{\boldsymbol{c}}$ \\
\hline A & 1 & 2 & 3 & 1.33 & 270 & 0.5 & 60 \\
B & 0.5 & 2 & 3 & 0.8 & 270 & 0.25 & 60 \\
C & 0.25 & 2 & 3 & 0.44 & 270 & 0.125 & 60 \\
\hline
\end{tabular}

Micro-channel plate

Inlet \& Outlet ports

Manifolds

PIR box

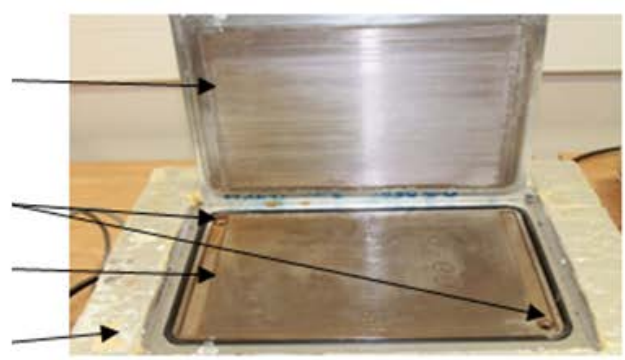

(a)

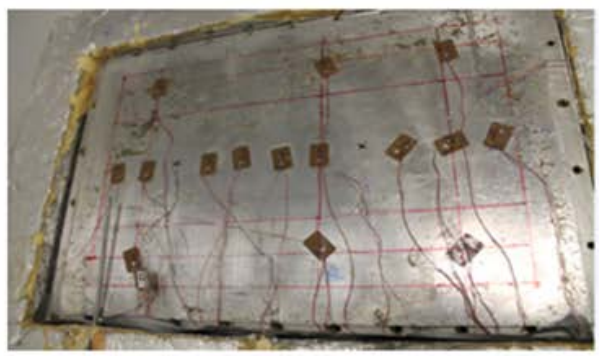

(b)

Figure 4: (a) Inner face of Test Rig (b) Thermocouple arrangement on plate 


\subsection{Data Reduction and Uncertainty}

Each test was run for 15 minutes to reach steady state and 200 data points were then captured. The sample standard deviation was typically $0.016{ }^{\circ} \mathrm{C}$. The parameters presented in Table 2 were calculated using the average of the captured data.

The Data Acquisition system has a function for calibrating all channels. This procedure compensates for the inaccuracies in the whole measurement system. The thermocouples were bonded together, put in the bath and calibrated at a number of temperatures to match bath temperature readout. Voltages from the mass flow meter were calibrated to match its display readout while the differential pressure sensor was calibrated to match a hand held manometer. The mass flow meter was also checked by timing flow into a measuring cylinder.

After calibration, steady state measurements were recorded for about 15 minutes. The standard deviation observed in each parameter was taken as the instrument's uncertainty. Uncertainties in geometric parameters were estimated using high precision measuring instruments as well as manufacturers' specifications. The deviations were used to estimate the uncertainties in the calculated values, assuming that the deviations in each term were uncorrelated. For example, equation (2) [37] was used to estimate the uncertainty in the heat transfer coefficient. Further details can be found in [38].

$$
\omega_{h}=h\left[\left(\frac{\omega_{Q}}{Q}\right)^{2}+\left(\frac{\omega_{S_{c}}}{S_{c}}\right)^{2}+\left(\frac{\omega_{\Delta T_{p f}}}{\Delta T_{p f}}\right)^{2}\right]^{1 / 2}
$$

Table 2: Details of data reduction

\begin{tabular}{lccc}
\hline Parameter & Definition & Equation number & Uncertainty \\
\hline Aspect ratio & $\alpha=\frac{a}{b}$ & $(3)$ & 0.05 \\
Reynolds number & $R e=\left(\frac{\dot{m}}{a b N_{c}}\right) \frac{D_{h}}{\mu}$ & $(4)$ & $<10 \%$ \\
Mean plate temperature & $\sum_{p}^{n} T_{p i=}$ & $(5)$ & $0.06^{\circ} \mathrm{C}$ \\
Mean fluid temperature & $T_{f}=\frac{T_{i n}+T_{\text {out }}}{2}$ & $(6)$ & $0.04^{\circ} \mathrm{C}$ \\
surface area of channels & $S_{c}=2 N_{c} L(a+b)$ & $(7)$ & $0.00115 \mathrm{~m}^{2}$ \\
Heat transferred to fluid & $Q=\dot{m} C_{p}\left(T_{\text {out }}-T_{\text {in }}\right)$ & $(8)$ & $7 \mathrm{~W}$ \\
Heat transfer coefficient & $h=\frac{Q}{S_{c}\left(T_{p}-T_{f}\right)}$ & $(9)$ & $<20 \%$ \\
Nusselt Number & $N u=\frac{h D_{h}}{k_{f}}$ & $(10)$ & $<20 \%$ \\
Thermal entry length & $L_{t}=0.05 R e P r D_{h}$ & $(11)$ & - \\
Friction factor & $\left.f=\Delta p \frac{D_{h}}{L} \frac{2}{\rho\left(\frac{\dot{m}}{N_{c} \rho a b}\right.}\right)^{2}$ & $(12)$ & $<25 \%$ \\
Poiseuille number & $P o=f R e$ & & $<30 \%$ \\
Pumping power per square meter & $P=\left(\frac{\dot{m}}{A_{p}}\right) \frac{\Delta p}{\rho}$ & $(13)$ & $<10 \%$ \\
\hline
\end{tabular}




\section{Results and Discussion}

\subsection{Thermal Performance}

Figure 5a shows measured heat transfer coefficients against fluid velocities; the three plates showed a strong dependence of heat transfer coefficient on fluid velocity, this relationship may be anticipated in some heat transfer cases as Çengel et al. [34] noted "In fact, the higher the fluid velocity, the higher the rate of heat transfer" [p.374]. At any given velocity, heat transfer coefficients from the three plates are however much lower than the predictions based on the standard $\mathrm{Nu}$ values. A heat transfer coefficient of $400 \mathrm{~W} / \mathrm{m}^{2}{ }^{\circ} \mathrm{C}$ (typical of these results) would be expected if the channels had $D_{h}=8 \mathrm{~mm}$. In fact the micro-channels had $D_{h}<1.33 \mathrm{~mm}$ and higher heat transfer coefficients were expected. From Figure $5 \mathrm{~b}$ it can be observed that the Nusselt numbers show some dependence on the Reynolds number, a trend resembling laminar predictions for flat plates turbulent flow as opposed to laminar pipe flow. It can also be observed that the Nusselt number increases as aspect ratio approaches unity. It should be noted that the entry length for all tests in the present study was less than $20 \%$ of channel length; its effects can therefore be neglected [25].

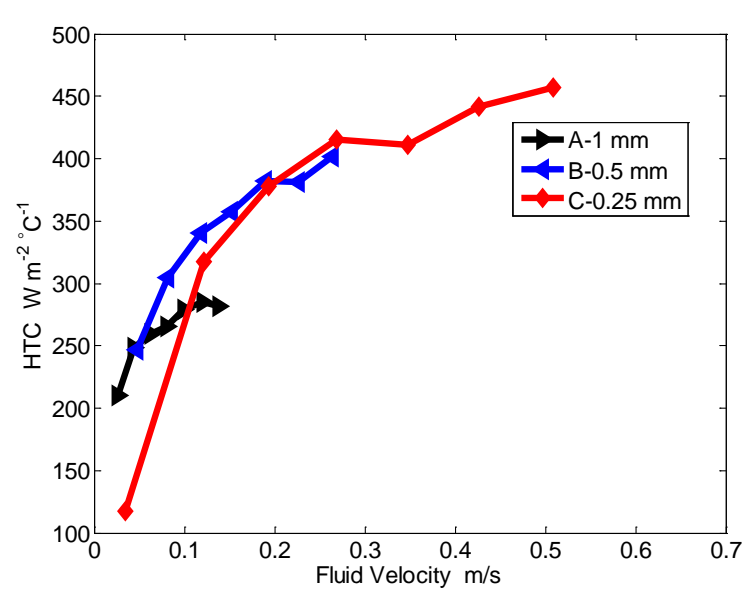

(a)

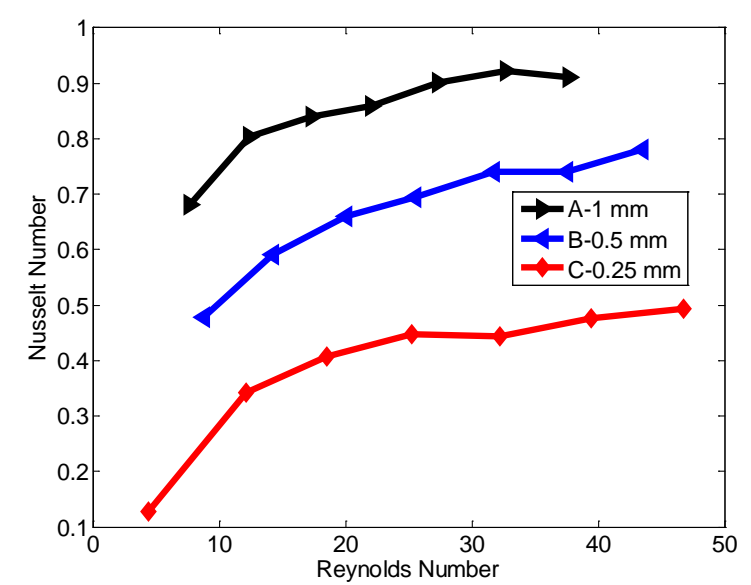

(b)

Figure 5: (a) Heat transfer coefficient versus fluid velocity (b) Nusselt number versus Reynolds number

Nusselt numbers of this order have been observed by several scholars who have experimentally and/or numerically studied heat transfer in micro-channels, for example, Dixit and Ghosh [16], Qu et al. [17], Peng et al. [13] and Wu and Cheng [28]. Reynolds number dependent Nusselt number correlations for micro-channels have also been proposed by Choi et al. [15], Peng and Peterson [14] and Peng et al. [13]. Various explanations have been postulated for these low Nusselt numbers. Celata et al. [39] attributed this to a heat loss term, Rahimi and Mehryar [40] and Nonino et al. [41] attributed it to conjugate heat transfer (axial heat conduction in the duct wall).

The deviation from theory in this study may be partly attributed to conjugate heat transfer. Firstly, due to the Reynolds number dependence observed; as the Reynolds number increases, axial conduction effects in the channel walls decrease. Secondly, the thickness and thermal conductivity of the micro-channel walls and slabs will promote thermal conduction in the axial direction. Therefore, the negative effect of conjugate heat transfer on thermal performance can be suppressed by having micro-channel geometries with thin walls. This type of channel can 
be achieved by hydroforming thin metal plates. Effects of conjugate heat transfer can be further suppressed by ensuring the flow rate through the collector is high enough to yield Reynolds numbers which result in the effects of conjugate heat transfer being negligible.

Gamrat et al. [18] observed that the position of the thermocouples away from the liquid/solid interface can yield as much as $40 \%$ uncertainty in the estimated Nusselt number. The thermocouple position might have also contributed to the low Nusselt numbers observed in the present study. Thermocouples might have been reading a temperature at the interface (top slab/micro-channel plate) rather than the plate temperature if there was significant thermal contact resistance between thermocouple tips and plate. Similarly, thermocouple tips were at least $2 \mathrm{~mm}$ from the liquid/solid interface. Several attempts to rectify this were made; the preferred option was to use adhesive fibre-glass pads on the thermocouple tips. These pads ensured the tips were securely fixed to the micro-channel plate and acted as a form of insulation from the interface and/or top slab.

Thermocouples were calibrated before and checked after the experiments and the three plates were tested under identical experimental setups. Therefore, even though the position of the thermocouples may yield some uncertainty in the absolute values of Nusselt numbers; it will have no effect on the relative values. In other words, the results can still be qualitatively compared with minimal uncertainty. However, to be able to compare the results with numerical models or literature, these uncertainties must be accounted for. The correction of temperature measurement was estimated using Fourier's law. The interface thickness was estimated by measuring the mean total thickness of the assembled test rig and subtracting it from the sum of the individual component thicknesses. This thickness was then used to estimate the temperature gradient across the interface ( $\Delta T_{\mathrm{int}}$ ); the plate temperature was corrected, assuming thermocouples were measuring the temperature at the middle of the interface, equation(15). The error bars account for other uncertainties discussed in section 3.2

$$
T_{p, \text { corrected }}=T_{p}-\left(\frac{\Delta T_{\text {int }}}{2}+\Delta T_{\text {MCplate }}\right)
$$

Where $\Delta T_{\mathrm{MCplate}}$ is the temperature difference between the fluid solid interface and the top face of the micro-channel plate.

Figure 6a shows plots comparing the corrected Nusselt numbers with predictions [35] for a channel with all four sides transferring heat under a $\mathrm{H} 2$ wall boundary condition. Though the value of the Nusselt number differs, a similar trend can be observed in the predicted [35] and measured Nusselt numbers. (i.e. Nusselt number increases as aspect ratio approaches unity). Figure $6 \mathrm{~b}$ is a similar plot but at a fluid inlet temperature of $20^{\circ} \mathrm{C}$. 


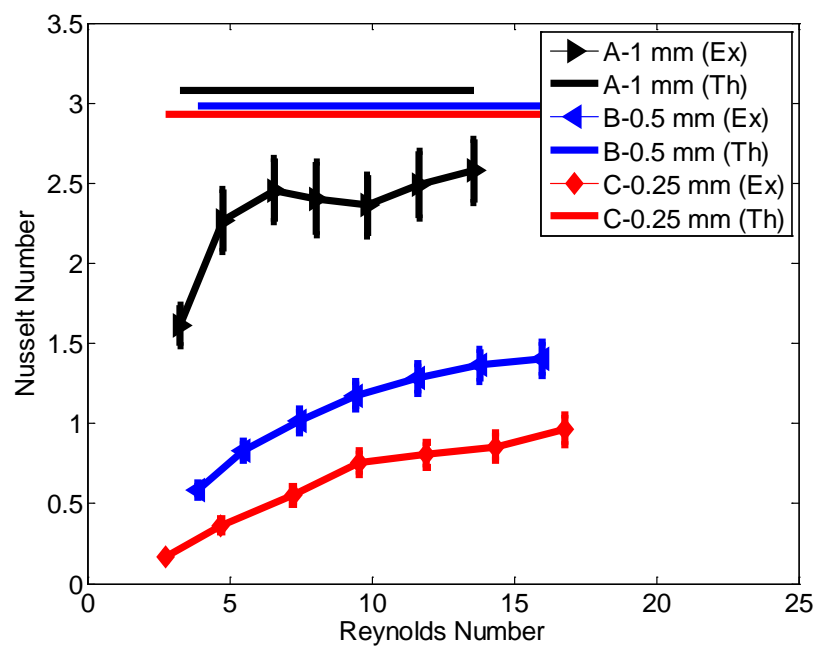

(a)

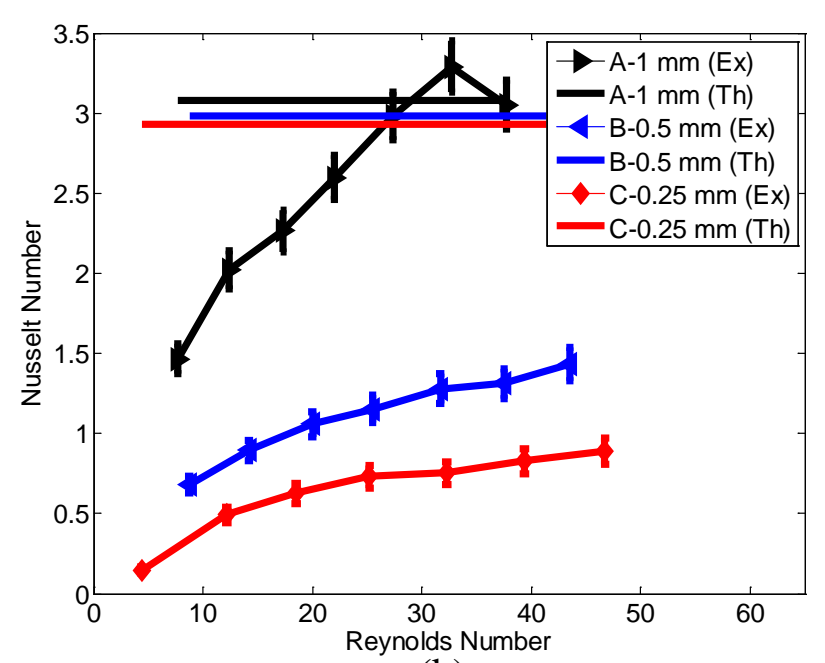

(b)

Figure 6: Comparing experimental results with theory (a) $\mathrm{T}_{\text {in }}=5^{\circ} \mathrm{C}$ (b) $\mathrm{T}_{\text {in }}=20^{\circ} \mathrm{C}$

Previous studies have produced a variety of empirical correlations, including:

- Peng et al. [13], $N u_{\text {peng et al. }}=0.038 \operatorname{Re}^{0.62} \operatorname{Pr}^{0.333}$

- Peng and Peterson [14], $N u_{\mathrm{p} \& \mathrm{p}}=0.1165 \alpha^{-0.79} \operatorname{Re}^{0.62} \operatorname{Pr}^{0.333}\left(\frac{D_{h}}{p}\right)^{0.81}$

- Choi et al. [15], $N u_{\text {Choi }}=0.000972 \operatorname{Re}^{1.172} \operatorname{Pr}^{0.333}$

Figure 7 compares the experimental result with these correlations; the experimental data can be observed to be in the range of correlations by Peng et al. [13] and Choi et al. [15]. The correlation of Peng and Peterson [14], which is also aspect ratio dependent, yields Nusselt numbers that lie between these experiments and traditional correlations. The trend from this correlation is however opposite of that observed (i.e. $N u_{\mathrm{p} \& \mathrm{p}}$ reduces as aspect ratio tends to unity). The thermal performance of these plates are similar in trend to predictions from $\mathrm{H} 2$ (with 0 or 1 adiabatic wall) or H1 (with 3 adiabatic walls) boundary condition. The Nusselt number increases as aspect ratio approaches unity.

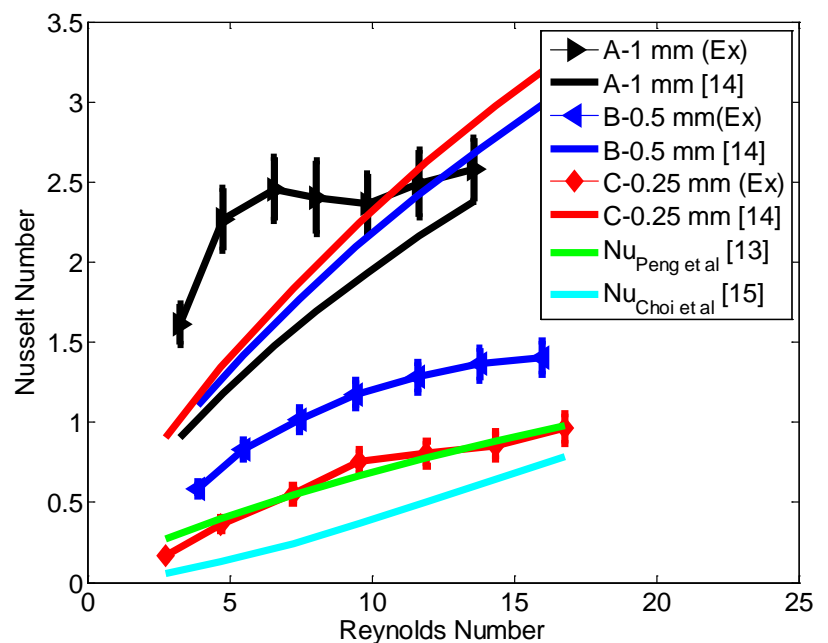

(a)

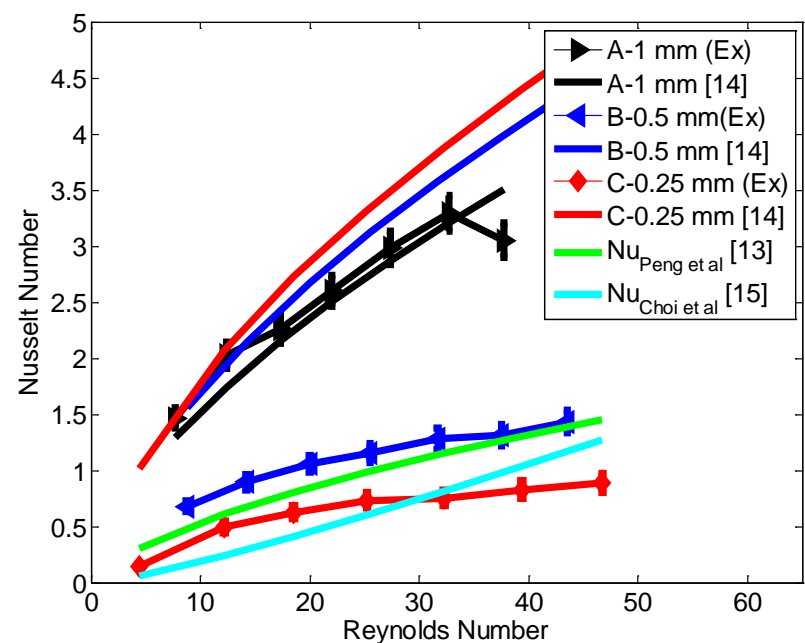

(b)

Figure 7: Comparing results with micro - channel correlations (a) $\mathrm{T}_{\text {in }}=5^{\circ} \mathrm{C}$ (b) $\mathrm{T}_{\text {in }}=20^{\circ} \mathrm{C}$ 
The results suggest a similar heat sinking performance (heat transfer coefficient) for the three plates, despite a difference of up to $65 \%$ in hydraulic diameters. This implies that reducing the channel size only provides marginal improvements. This trend is advantageous from a manufacturing perspective as smaller channels are potentially more expensive to fabricate due to the higher precision required. It also has the benefit of requiring less power for pumping.

\subsection{Hydraulic Performance}

Figure 8a shows measured pressure drop against fluid velocity; a linear relationship between velocity and pressure drop is observed, as expected. In fact, the three curves can be approximated as one. A similar observation was noted by Hetsroni et al. [42]. This results suggests that in the range studied, the geometry design has negligible effects on the pressure drop however, the rate of fluid flow has more significant effects. Therefore, the pressure drop is more dependent on fluid velocity rather than geometry.

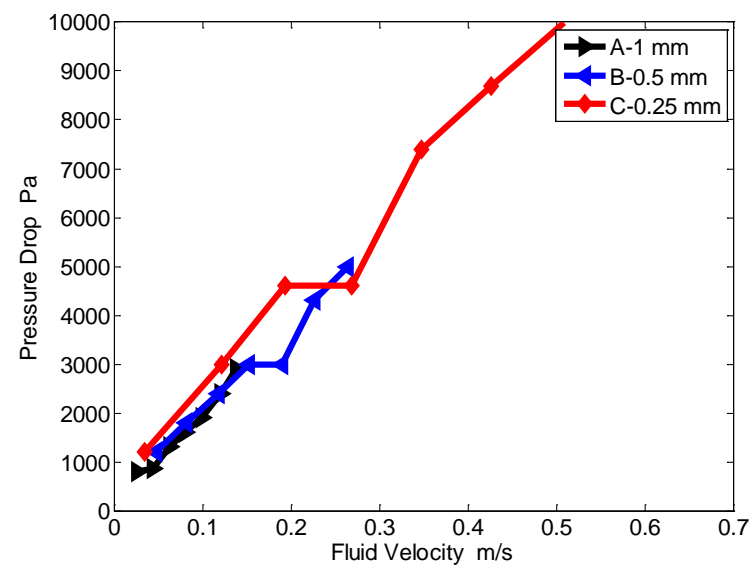

(a)

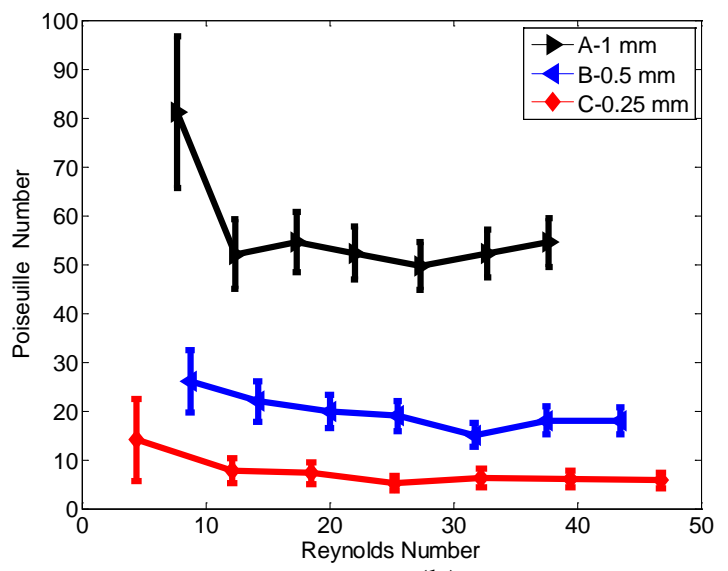

(b)

Figure 8: (a) Pressure drop versus fluid velocity (b) Poiseuille number versus Reynolds number

Figure 8b shows plots of Poiseuille numbers against Reynolds number; curves which can be approximated as horizontal lines are observed. This indicates that the flow can be approximated as a Poiseuille flow (i.e. $d P o / d R e=0$ [43]), therefore, at a specified flow rate, the required pumping power is proportional to the length of the channel and the viscosity of the fluid but inversely proportional to the fourth power of the hydraulic diameter. Channels with larger hydraulic diameters will therefore be preferred to minimise the pumping power.

Figure 9a compares measured friction factors with predictions [44] based on numerical Poiseuille numbers for rectangular channels. A similar trend of friction factor reducing with Reynolds number can be observed although measured friction factors are slightly lower than predicted values. Lower friction factors in micro-channels have been observed in other studies, principally for gas flows [15, 45], but also for liquid flows [46, 47]. Lower friction factors observed in the present study may be attributed to the significant fluid temperature rise in the flow direction which is a result of low flow velocities. Fluid temperature rise can have significant effects on the frictional characteristics; for example, when Tyfocor rises from $5^{\circ} \mathrm{C}$ to $10^{\circ} \mathrm{C}$, the kinematic viscosity decreases by about $40 \%$ which results in a corresponding $40 \%$ increase in the local Reynolds number. Since the laminar friction factor is inversely 
proportional to the Reynolds number $(f=P o / R e)$, an increase in local Reynolds number in the flow direction will result in lower average friction factors. This also explains the lower Poiseuille numbers observed in Figure 8b; at a given pumping power, smaller channels will have lower flow rates which will yield higher fluid temperature rise and consequently a lower Poiseuille number.

A plot of the pump power per collector area against fluid velocity is shown in Figure 9b. It indicates that the smaller the channel, the lower the power required for a given fluid velocity. This agrees with the predictions of Moss and Shire [31], however, their predictions further show that increasing the channel size slightly can improve performance at a pumping power requirement of less than $2 \%$ of collected solar energy. Therefore, larger channels may be used; this should be sized based on pumping power limit, required fluid temperature rise and fluid properties.

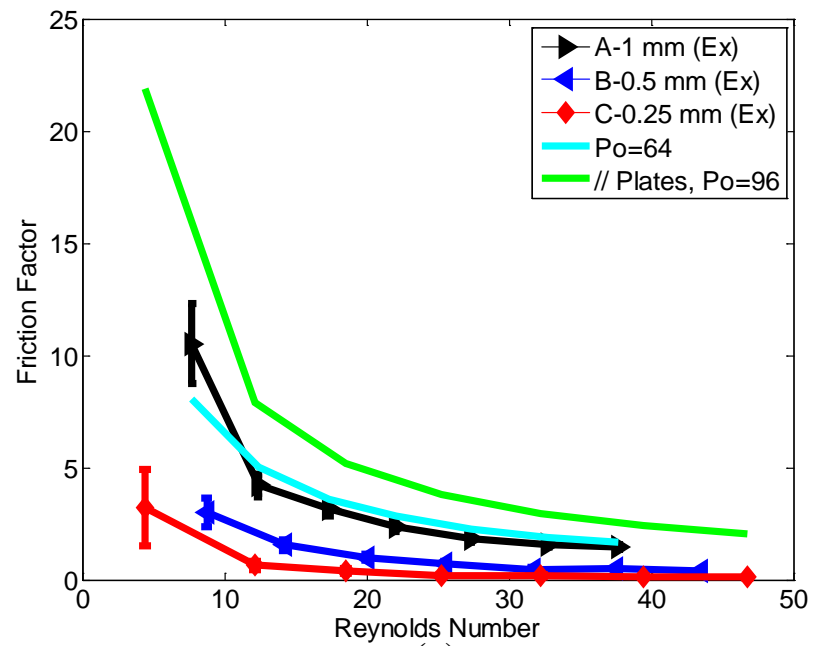

(a)

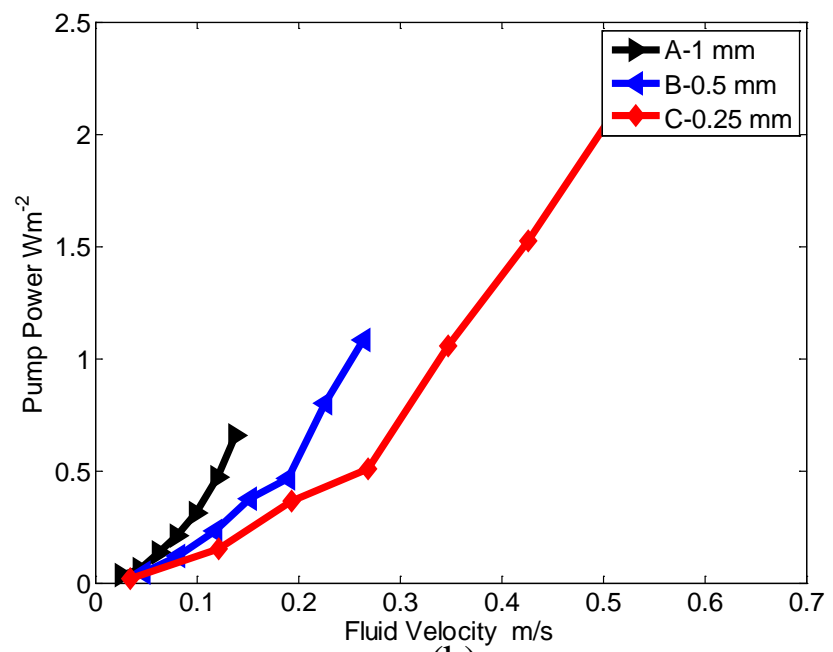

(b)

Figure 9: (a) Friction factor versus Reynolds number (b) Pumping power versus fluid velocity

\subsection{Thermo-Hydraulic Performance}

Figure 10 shows heat transfer coefficient against pump power. The curves can be seen to exhibit a profile similar to a power function whose exponent is between 0 and -1 ; the heat transfer coefficient flattens out at about $0.3 \mathrm{~W} / \mathrm{m}^{2}$; this indicates that beyond this power level, marginal improvement in thermal performance will be achieved. Plate $\mathrm{C}$ yielded the best heat transfer coefficient per pumping power input which might be attributed to the lower volumetric flow rate in this plate (i.e. the channels are smaller and therefore will accommodate less fluid). The curves of Plates B and C show similar heat transfer coefficient per pumping power despite the $50 \%$ difference in aspect ratio.

Lower pump power yields higher overall fluid temperatures due to lower fluid velocities. The fluid must therefore be pumped at higher velocities to achieve the solar collector's primary objective, of collecting absorbed heat with the fluid. Figure 10 shows that pump power per square meter of absorber plate is a minute fraction of the thermal energy typically absorbed; a solar photovoltaic system can be used to supply this power. Thermal performance is therefore of greater importance than the pump power. It is recommended that the collector should 
operate in the top left quadrant of Figure 10 (above $h=250 \mathrm{~W} / \mathrm{m}^{2}{ }^{\circ} \mathrm{C}$ ) which will result in $\Delta T_{p f}<4^{\circ} \mathrm{C}$ under an incident heat flux of $1000 \mathrm{~W} / \mathrm{m}^{2}$. The maximum pump power to be expended can be determined based on the minimum overall fluid temperature rise required.

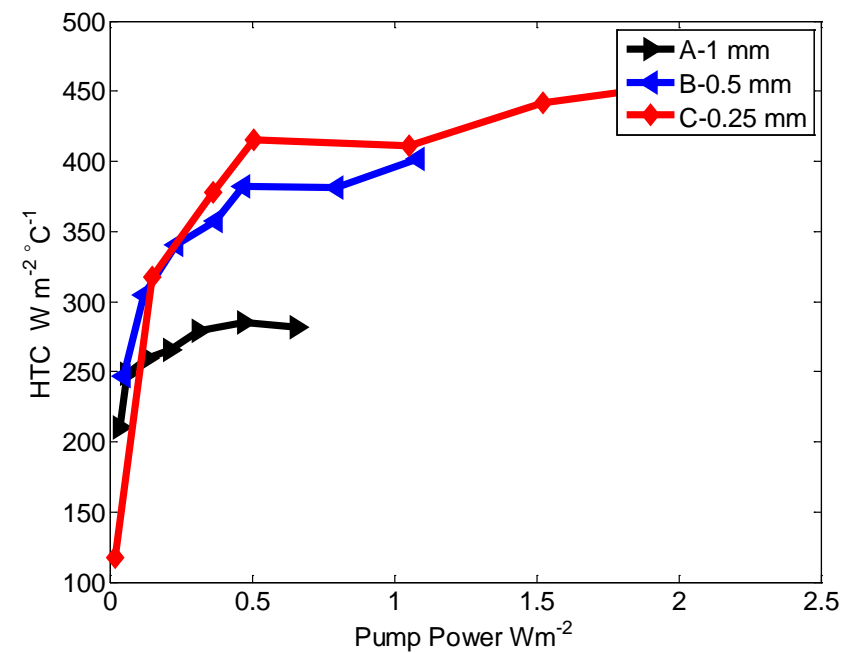

Figure 10: Heat transfer coefficient versus pumping power

\section{Conclusion}

Experimental analyses have been carried out on three micro-channel plates. Conventional correlations for rectangular channels were found to over-predict the thermal performance of the plates. The results showed a strong dependence of heat transfer coefficient on fluid velocity. Nusselt number was dependent on Reynolds number, a trend which has been attributed to axial thermal conduction. The Nusselt number was found to increase as the aspect ratio approached unity. This signifies that the design of micro-channel absorber plates can be slightly enhanced by adopting geometry with channel aspect ratio close to unity.

It was also observed that reducing the hydraulic diameter of the channels results in only a marginal improvement in thermal performance, therefore, plates with slightly larger channels can be used to achieve a similar thermal performance. Larger channels are potentially cheaper to manufacture and will most likely reduce the pumping power required for a given thermal performance since at a given flow rate, the pumping power is inversely proportional to the fourth power of the hydraulic diameter.

Experimentally measured friction factors were similar in trend to published data although slightly lower than predicted values based on numerical Poiseuille numbers for rectangular channels. This has been attributed to the change in viscous properties of the fluid in the flow direction resulting from increase in fluid temperature. The results showed that significant thermal improvements can be achieved by increasing the fluid velocity albeit at the expense of increased pumping power; this improvement is aspect ratio independent and becomes marginal above a pumping power of $0.3 \mathrm{~W} / \mathrm{m}^{2}$. There is an advantage in expending more power above this level to increase fluid velocity as it reduces the overall temperature rise (which also reduces thermal losses). The trends observed in this experimental study agrees with the theory presented by Moss and Shire [31]. 
In practice, optimum micro-channel geometry in plates will need to be sized based on fluid properties and operating conditions. The micro-channels should also have thin walls to minimise the effects of conjugate heat transfer. A sustainable energy technology should be installed alongside to provide pumping power required to minimise the overall fluid temperature rise. The results are beneficial for the design and operation of micro-channel absorber plates.

\section{Acknowledgments}

This research used equipment through the Science City Energy project, part funded by the European Regional Development Fund, ERDF.

\section{References}

[1] Celata, G. P., "Heat transfer and fluid flow in microchannels," Boiling and evaporation, 2004.

[2] Tripanagnostopoulos, Y., Souliotis, M., and Nousia, T., "Solar collectors with colored absorbers," Solar Energy, vol. 68, pp. 343-356, 2000.

[3] Matuska, T. and Sourek, B., "Façade solar collectors," Solar Energy, vol. 80, pp. 14431452, 2006.

[4] Chaurasia, P. B. L., "Solar water heaters based on concrete collectors," Energy, vol. 25, pp. 703-716, 2000.

[5] Hestnes, A. G., "Building Integration Of Solar Energy Systems," Solar Energy, vol. 67, pp. 181-187, 1999.

[6] Kundu, B., "Performance analysis and optimization of absorber plates of different geometry for a flat-plate solar collector: a comparative study," Applied Thermal Engineering, vol. 22, pp. 999-1012, 2002.

[7] Farahat, S., Sarhaddi, F., and Ajam, H., "Exergetic optimization of flat plate solar collectors," Renewable Energy, vol. 34, pp. 1169-1174, 2009.

[8] Khamis Mansour, M., "Thermal analysis of novel minichannel-based solar flat-plate collector," Energy, vol. 60, pp. 333-343, 2013.

[9] Sharma, N. and Diaz, G., "Performance model of a novel evacuated-tube solar collector based on minichannels," Solar Energy, vol. 85, pp. 881-890, 2011.

[10] Deng, Y., Wang, W., Zhao, Y., Yao, L., and Wang, X., "Experimental study of the performance for a novel kind of MHPA-FPC solar water heater," Applied Energy, vol. 112, pp. 719-726, 12// 2013.

[11] Shah, R. K. and London, A. L., Laminar flow forced convection in ducts : a source book for compact heat exchanger analytical data. New York: Academic Press, 1978.

[12] Holman, J. P., Heat transfer. Boston, [Mass.]: McGraw Hill Higher Education, 2010.

[13] Peng, X., Peterson, G., and Wang, B., "Heat transfer characteristics of water flowing through microchannels," Experimental Heat Transfer An International Journal, vol. 7, pp. 265-283, 1994.

[14] Peng, X. F. and Peterson, G. P., "Convective heat transfer and flow friction for water flow in microchannel structures," International Journal of Heat and Mass Transfer, vol. 39, pp. 2599-2608, 1996.

[15] Choi, S. B., Barren , R. R., and Warrington, R. Q., "Fluid flow and heat transfer in micro-tubes," ASME DSC pp. 89-93, 1991.

[16] Dixit, T. and Ghosh, I., "Low Reynolds number thermo-hydraulic characterization of offset and diamond minichannel metal heat sinks," Experimental Thermal and Fluid Science, vol. 51, pp. 227-238, 11// 2013. 
[17] Qu, W., Mala, G. M., and Li, D., "Heat transfer for water flow in trapezoidal silicon microchannels," International Journal of Heat and Mass Transfer, vol. 43, pp. 39253936, 11/1/ 2000.

[18] Gamrat, G., Favre-Marinet, M., and Asendrych, D., "Conduction and entrance effects on laminar liquid flow and heat transfer in rectangular microchannels," International Journal of Heat and Mass Transfer, vol. 48, pp. 2943-2954, 2005.

[19] Adams, T. M., Abdel-Khalik, S. I., Jeter, S. M., and Qureshi, Z. H., "An experimental investigation of single-phase forced convection in microchannels," International Journal of Heat and Mass Transfer, vol. 41, pp. 851-857, 1998.

[20] Celata, G. P., Cumo, M., Guglielmi, M., and Zummo, G., "Experimental investigation of hydraulic and single-phase heat transfer in 0.130-mm capillary tube," Microscale Thermophysical Engineering, vol. 6, pp. 85-97, 2002.

[21] Bucci, A., Celata, G. P., Cumo, M., Serra, E., and Zummo, G., "Water single-phase fluid flow and heat transfer in capillary tubes," in ASME 2003 1st International Conference on Microchannels and Minichannels, 2003, pp. 319-326.

[22] Lee, P.-S., Garimella, S. V., and Liu, D., "Investigation of heat transfer in rectangular microchannels," International Journal of Heat and Mass Transfer, vol. 48, pp. 16881704, 2005.

[23] Morini, G. L., "Scaling effects for liquid flows in microchannels," Heat Transfer Engineering, vol. 27, pp. 64-73, 2006.

[24] Hetsroni, G., Mosyak, A., Pogrebnyak, E., and Yarin, L. P., "Heat transfer in microchannels: Comparison of experiments with theory and numerical results," International Journal of Heat and Mass Transfer, vol. 48, pp. 5580-5601, 2005.

[25] Rosa, P., Karayiannis, T., and Collins, M., "Single-phase heat transfer in microchannels: the importance of scaling effects," Applied Thermal Engineering, vol. 29, pp. 3447-3468, 2009.

[26] Sobhan, C. B. and Garimella, S. V., "A comparative analysis of studies on heat transfer and fluid flow in microchannels," Microscale Thermophysical Engineering, vol. 5, pp. 293-311, 2001.

[27] Dixit, T. and Ghosh, I., "Review of micro- and mini-channel heat sinks and heat exchangers for single phase fluids," Renewable and Sustainable Energy Reviews, vol. 41, pp. 1298-1311, 1// 2015.

[28] Wu, H. and Cheng, P., "An experimental study of convective heat transfer in silicon microchannels with different surface conditions," International Journal of Heat and Mass Transfer, vol. 46, pp. 2547-2556, 2003.

[29] Naphon, P. and Khonseur, O., "Study on the convective heat transfer and pressure drop in the micro-channel heat sink," International Communications in Heat and Mass Transfer, vol. 36, pp. 39-44, 2009.

[30] Dogruoz, M. B., Arik, M., and Pautsch, A., "Heat transfer in microchannels: substrate effects and cooling efficiency for rectangular and circular ducts," in Thermal and Thermomechanical Phenomena in Electronic Systems (ITherm), 2010 12th IEEE Intersociety Conference on, 2010, pp. 1-7.

[31] Moss, R. and Shire, S., "Design and Performance of Evacuated Solar Collector Microchannel Plates," in EuroSun 2014 Conference, Aix-les-Baines, France, 2014.

[32] Duffie, J. A. and Beckman, W. A., Solar engineering of thermal processes. Hoboken, N.J.: Wiley, 2006.

[33] Rommel, M. and Moock, W., "Collector efficiency factor F'for absorbers with rectangular fluid ducts contacting the entire surface," Solar energy, vol. 60, pp. 199207, 1997.

[34] Çengel, Y. A., Ghajar, A. J., and Kanoglu, M., Heat and mass transfer fundamentals and applications. New York: McGraw Hill Higher Education, 2011. 
[35] Dharaiya, V. V. and Kandlikar, S. G., "Numerical Investigation of Heat Transfer in Rectangular Microchannels Under H2 Boundary Condition During Developing and Fully Developed Laminar Flow," Journal of Heat Transfer, vol. 134, pp. 020911020911, 2011.

[36] Tondeur, D., Fan, Y., Commenge, J.-M., and Luo, L., "Flow and pressure distribution in linear discrete "ladder-type" fluidic circuits: an analytical approach," Chemical Engineering Science, vol. 66, pp. 2568-2586, 2011.

[37] Holman, J. P., Experimental methods for engineers. Boston: McGraw-Hill/Connect Learn Succeed, 2012.

[38] Oyinlola, M. A., Shire, G. S. F., and Moss, R. W., "Thermal analysis of a solar collector absorber plate with microchannels," Experimental Thermal and Fluid Science, vol. 67, pp. 102-109, 2015.

[39] Celata, G., Cumo, M., Marconi, V., McPhail, S., and Zummo, G., "Microtube liquid single-phase heat transfer in laminar flow," International Journal of Heat and Mass Transfer, vol. 49, pp. 3538-3546, 2006.

[40] Rahimi, M. and Mehryar, R., "Numerical study of axial heat conduction effects on the local Nusselt number at the entrance and ending regions of a circular microchannel," International Journal of Thermal Sciences, vol. 59, pp. 87-94, 2012.

[41] Nonino, C., Savino, S., Del Giudice, S., and Mansutti, L., "Conjugate forced convection and heat conduction in circular microchannels," International Journal of Heat and Fluid Flow, vol. 30, pp. 823-830, 2009.

[42] Hetsroni, G., Gurevich, M., Mosyak, A., and Rozenblit, R., "Drag reduction and heat transfer of surfactants flowing in a capillary tube," International Journal of Heat and Mass Transfer, vol. 47, pp. 3797-3809, 8// 2004.

[43] Hetsroni, G., Mosyak, A., Pogrebnyak, E., and Yarin, L. P., "Fluid flow in microchannels," International Journal of Heat and Mass Transfer, vol. 48, pp. 1982-1998, 2005.

[44] Çengel, Y. A. C. J. M., Fluid mechanics : fundamentals and applications. Boston, Mass. [u.a.]: McGraw-Hill, 2010.

[45] Harley, J. C., Huang, Y., Bau, H. H., and Zemel, J. N., "Gas flow in micro-channels," Journal of Fluid Mechanics, vol. 284, pp. 257-274, 1995.

[46] Xu, B., Ooi, K., Wong, N., Liu, C., and Choi, W., "Liquid flow in microchannels," in Proceedings of the 5th ASME/JSME Joint Thermal Engineering Conference, 1999, pp. 1-7.

[47] Judy, J., Maynes, D., and Webb, B., "Liquid flow pressure drop in microtubes," in International Conference on Heat Transfer and Transport Phenomena in Microscale, Banff, Canada, 2000, pp. 149-154. 